\title{
Signals 1, 2 and B cell fate or: Where, when and for how long?
}

\author{
Jackson S. Turner | Zachary L. Benet | Irina L. Grigorova (D)
}

Department of Microbiology and Immunology, University of Michigan Medical

School, Ann Arbor, Michigan, USA

\section{Correspondence}

Irina L. Grigorova, Department of

Microbiology and Immunology, University of Michigan Medical School, 1150 W. Medical

Center Drive, 6748 MSII, Ann Arbor, MI

48109.

Email: igrigor@umich.edu

Funding information

National Institutes of Health, Grant/Award

Number: R01 Al106806

\begin{abstract}
Diverse B cell responses are important for generating antibody-mediated protection against highly variable pathogens. While some antigens can trigger T-independent $B$ cell proliferation and short-term antibody production, development of long-term humoral immunity requires T-dependent B cell responses. The "two-signal" model of $B$ cell activation has long been invoked to explain alternate B cell recruitment into immune response to foreign antigens vs. induction of tolerance to self-antigens. However, a number of other factors appear to influence the fate of mature B cells responding to antigen in vivo. In this review, we will discuss how various spatiotemporal scenarios of antigen access into secondary lymphoid organs, antigen valency and cellular environment of antigen acquisition by $B$ cells, duration of $B$ cell access to antigen and the timing of $T$ cell help may affect follicular B cell fate, including death, survival, anergy, and recruitment into T-dependent responses. We will also highlight unresolved questions related to $B$ cell activation and tolerance in vivo that may have important implications for vaccine development and autoimmunity.
\end{abstract}

KEYWORDS

activation-induced cell death, B cell receptor signaling, T cell help, T-dependent B cell

response, tolerance

\section{1 | TWO-SIGNAL MODEL OF B CELL ACTIVATION}

Bretcher and Cohn's two-signal hypothesis of lymphocyte activation predicts that antigen $(\mathrm{Ag})$ receptor signaling alone is insufficient for full activation of lymphocytes and their differentiation into effector cells. ${ }^{1,2}$ While highly crosslinking-Ags, for example, bacterial capsular polysaccharides and repetitive motifs in viral capsids, induce prolonged and persistent B cell receptor (BCR) signaling in B cells that can bypass the requirement of secondary signals, ${ }^{3-5}$ in most physiological settings the "second signal" is necessary for B cell proliferation and differentiation into antibody (Ab)-secreting plasma cells (PCs). These signals may be provided by various molecular factors

This article is part of a series of reviews covering $\mathrm{B}$ and $\mathrm{Th}$ cell response to $\mathrm{Ag}$ in vivo: implications for vaccine development and diseases appearing in Volume 296 of Immunological Reviews. and cellular sources. ${ }^{6} \mathrm{~B}$ cell responses that require secondary, contact-dependent (cognate) signals from helper T cells (Th) are called T-dependent. T-independent responses encompass all other scenarios that trigger B cell proliferation and differentiation into PCs.

\section{1 | T-independent responses}

In the absence of T cell help, toll-like receptor ligands from microbial components (PAMPs), for example, lipopolysaccharides (LPS), or cell damage-associated ligands (DAMPs) may synergize with BCR signaling to promote $B$ cell responses. Other accessory signals include BAFF and April TNF-family members, CD40 ligand, and cytokines, IL21, IL4, IL6, IL10, and IL21. These signals may be initiated under specific conditions by various types of innate or innate-like cells, such as iNKT cells, neutrophils, monocyte-derived cells and/or dendritic 
cells (DCs), and possibly mast cells. T-independent responses are predominantly mounted by B1 and MZ B cells and lead to low affinity, short-term IgM antibody-mediated humoral immunity (reviewed in Ref. 6). However, in some cases they can generate long-lived Ab and memory responses or synergize with $\mathrm{T}$ cell-derived signals to modulate or potentiate $B$ cell responses. ${ }^{7-12}$

\section{2 | T-dependent responses}

Efficient generation of long-lived memory and plasma cells (PC) and generation of high-affinity Abs to Ags that contain proteins or peptides require $T$ cells and thus are referred to as T-dependent antibody responses. Activated $\mathrm{B}$ cells internalize Ag-bound BCRs and direct them to endosomes, where antigenic proteins are processed into peptides and loaded onto major histocompatibility complex II (MHCII) molecules. T-helper (Th) cells that recognize pMHCII/peptide complexes presented on Ag-primed B cells through their $\mathrm{T}$ cell receptor (TCR) can engage in cognate interactions and provide particularly potent B cell-stimulating factors, including the following: SLAM family members, CD40 ligand and cytokines such as IL21 and IL4 that promote B cell survival, proliferation and differentiation (reviewed in Ref. 13). As in T-independent responses, in T-dependent responses $\mathrm{B}$ cells generate short-lived PCs and memory cells that express immunoglobulins of low affinity toward Ag. However, T-dependent Ags also lead to robust and prolonged formation of microanatomical structures in the B cell follicles of secondary lymphoid organs (SLOs) called germinal centers (GCs). ${ }^{13,14}$ Within GCs, B cells undergo a process called affinity maturation where cells expressing the highest affinity BCRs are selected. GCs give rise to high affinity, class-switched memory B cells, and long-lived PCs that migrate to the bone marrow, the gut or mammary glands, and can persist for months/years secreting high-affinity antibodies. ${ }^{15}$ Longlasting term, high affinity, class-switched Abs are a hallmark of the T-dependent humoral response. Thus, understanding the factors that control B cell recruitment into T-dependent responses is critical for design and implementation of measures that promote durable humoral immunity to pathogens, including improved vaccines.

Recruitment of epitope-specific $B$ cells into immune response depends on the initial frequency of these $B$ cells in the circulation. ${ }^{16-18}$ At the same time, participation of individual B cell clones in the T-dependent responses is limited by the avidity of their interaction with $\mathrm{Ag}^{19,20}$ and $\mathrm{B}$ cell apoptosis. ${ }^{21}$ While $\mathrm{B}$ cell $\mathrm{Ag}$ acquisition and presentation to Th cells, as well as cognate T-helper signals are known to be essential, ${ }^{13,22}$ other features that affect survival and recruitment of activated B cells into T-dependent response are less well understood.

In this review, we will consider the additional factors that can vary in an immune responses to infection or immunization, and may affect individual $B$ cell's recruitment into T-dependent responses vs development of tolerance and/or antigen-induced cell death (AICD). We will focus on the early events in the recruitment of follicular $B$ cells into T-dependent responses since these are the dominant B cell population in SLOs and the main responders to T-dependent Ags.

\section{2 | SPATIOTEMPORAL SCENARIOS OF FOLLICULAR B CELL ACTIVATION}

The first step in B cell activation is the BCR-mediated binding to $\mathrm{Ag}$ that leads to BCR signaling, Ag internalization, processing, and loading of antigenic peptides on $\mathrm{MHCll}$ that, along with upregulated accessory molecules, for example, CD86, provide signals to Th cells. This must be followed by acquisition of cognate help from Th cells. The spatiotemporal dynamics of these events depends greatly on the anatomy of SLOs, the types of Ags that reach SLOs by passive drainage or active delivery, ${ }^{23-26}$ and multiple molecular cues that orchestrate movements of lymphocytes within SLOs at different stages of their activation. ${ }^{27}$ In this section, we will provide an overview of various spatiotemporal scenarios of follicular B cell activation in SLO. In the following sections, we will discuss how variable timing and cellular context of B cell exposure to $\mathrm{Ag}$ and $\mathrm{T}$ cell help in SLO may affect B cell recruitment into T-dependent responses.

\section{1 | Anatomy of spleen, lymph nodes, and peyer's patches}

The lymph nodes (LNs) and the white pulp of the spleen are comprised of a central T zone bordered by B cell follicles with interfollicular regions (in LNs) or bridging channels (in spleen) between adjacent follicles that are more enriched with T cells, macrophages (M $\Phi)$, and dendritic cells (DCs) (Figure 1A,B). Within the spleen, follicles are bordered by the marginal zone (MZ) that is quickly exposed to Ags following their entry into the bloodstream, while within the LNs follicles are adjacent to the subcapsular sinus (SCS), where lymph-born Ags from the upstream lymphatics are delivered (Figure 1). Both the sinuses and interfollicular areas/bridging channels contain specialized cells that facilitate $\mathrm{Ag}$ capture and presentation. ${ }^{27,28}$ The structure of peyer's patches (PP) is somewhat distinct. While small T cell zones are present there as well, PP are dominated by B cell follicles, follicle-associated epithelium (FAE), and sub-epithelial dome (SED) that is positioned between FAE and follicles. Luminal Ags are transported through FAE-associated $M$ cells and are quickly spread within DC-rich SEDs. ${ }^{29}$ While spatial/temporal access of luminal Ags into $B$ cell follicles in PP is not yet well characterized, it has been extensively described for rodent LNs and spleen.

\subsection{How B cells encounter antigen}

Ags distribution and its acquisition by specific B cells have been shown to depend on a number of factors, including Ag size, route of entry, and availability of preexisting Ag-specific Abs and their isotypes. ${ }^{23-26}$ Ags of various sizes have differential access to the SLO parenchyma. ${ }^{30,31}$ Smaller Ags ( $<70 \mathrm{kDa}$ ) can enter B cell follicles from the $\mathrm{SC}$ or $\mathrm{MZ}$ sinuses through follicular conduits and to some extent via direct diffusion across the floor of the sinus ${ }^{32-35}$ and can rapidly access $\mathrm{Ag}$-specific $\mathrm{B}$ cells in the follicles (Figure $1 \mathrm{C}$ ). 
(A)

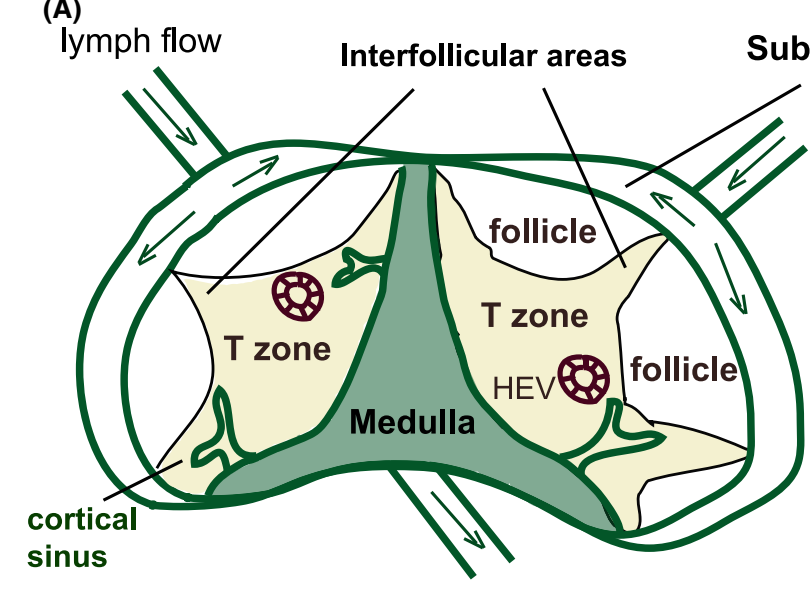

(B)

(C)

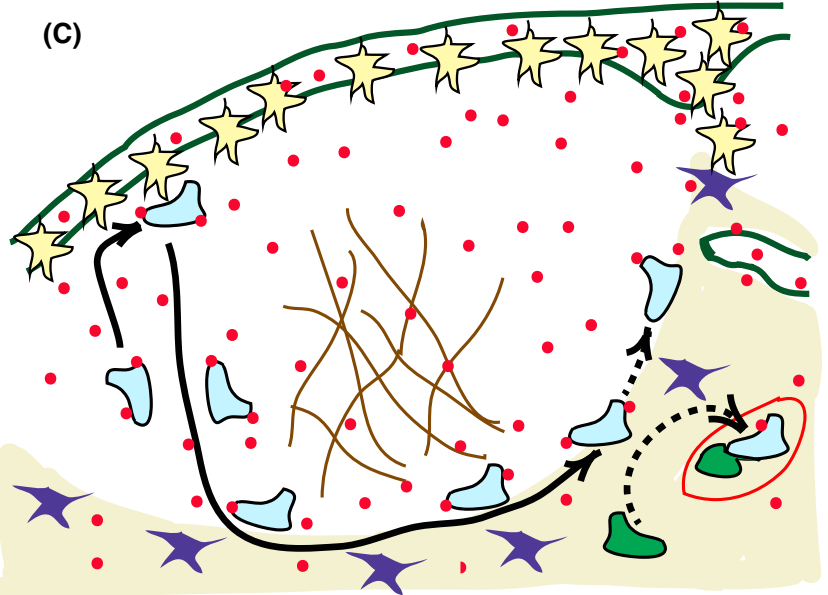

is SCS Macrophage D Dendritic cell ilar sinus

follicle
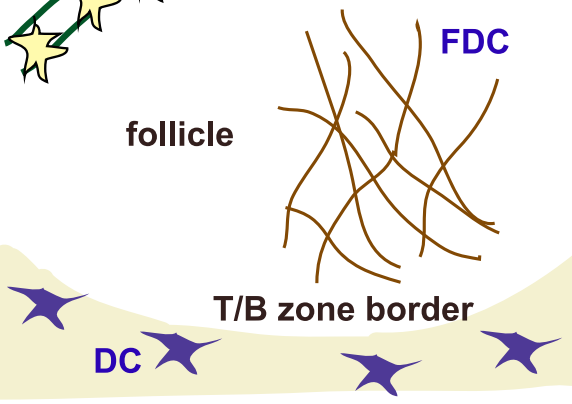

T zone

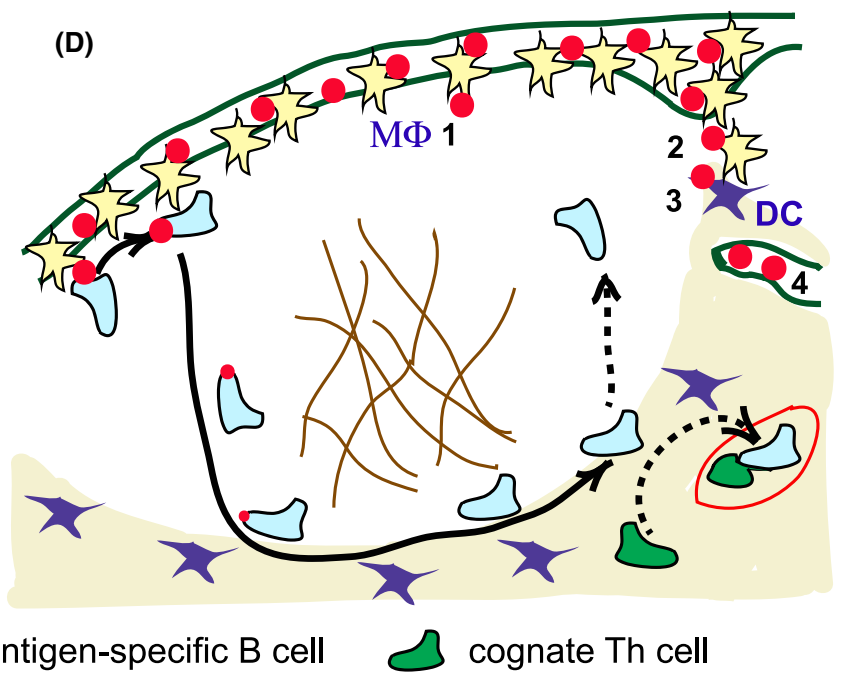

Draining antigens: $\begin{aligned} & <70 \mathrm{kDa} \\ & >70 \mathrm{kDa}\end{aligned}$

FIGURE 1 Spatiotemporal scenarios of B cell encounters with cognate Ags in draining LNs during the primary immune responses. A, B, Schematics of lymph node (A) and lymph node fragment (B) anatomy. C, D, Scenarios of the small soluble ( $<70 \mathrm{kDa}$, in C) and large (>70 kDa, in D) Ag access into the draining LNs, Ag-dependent activation of cognate B cells and their relocalization in the follicles. C, Small Ags permeate $B$ cell follicles promoting rapid exposure of Ag-specific B cells to the Ag. D, The access of large Ags into LN parenchyma is restricted. B cells may acquire large Ags from the subcapsular sinus (SCS) and SCS macrophages, M $\Phi$ (1), interfollicular or medullary regions (2), from dendritic cells (DCs) that bring the Ag from the site of infection (3), or cortical LYVE1 + lymphatic sinuses (4). In primary immune response after Ag-dependent activation cognate B cells upregulate Ebi2 and move to the back of the follicles. They then upregulate CCR7 and move to the B-T zone interface, where they may encounter cognate Th cells. The initial duration of B cell exposure to large Ags in SLO is likely to be transient, in contrast to the more continuous exposure to small soluble Ags. In the presence of immune complexes, Ags are rapidly (12-24 h) transported and deposited onto follicular dendritic cells (FDCs). In that case, B cells may be more likely to encounter Ag in a recurrent fashion on FDCs (not shown). Red circle: interaction between cognate $B$ and Th cells

In contrast, large Ags (eg, viruses, bacteria, and large proteins and protein complexes) initially localize to a few restricted locations (Figure 1D). In the LNs, these locations include interfollicular and medullary regions, SC, and cortical, as well as medullary lymphatic sinuses. ${ }^{35-39}$ B cells migrate to these regions in a random fashion and can acquire their cognate Ags at these sites, in some cases in association with local macrophages or DCs. Intravital imaging studies visualizing B cell acquisition of Ags from SCS macrophages found that these encounters were relatively brief (ranging from
5 minutes to a few tens of minutes). ${ }^{36,37}$ Additionally, B cells may acquire large Ags from DCs that migrate to the LNs and bring internalized Ags from upstream lymphatics to the interfollicular areas and T-B border. ${ }^{40} \mathrm{~A}$ non-degradative pathway of $\mathrm{Ag}$ recycling observed in DCs promotes retention of some intact $A g$ for $B$ cell acquisition. ${ }^{41}$

Pre-existing Abs or direct $\mathrm{Ag}$ binding of complement component $\mathrm{C} 3 \mathrm{~b}$ can lead to rapid redistribution of Ags from the restricted regions described above to the center of the follicles. The immune 
complexes are transported by naive B cells in the $L N$ s or $M Z B$ cells in the spleen and deposited on follicular dendritic cells (FDCs), large stromal cells located near the middle of the follicle that have extensive dendritic processes, and high expression of the complement receptors CD21 (CR2) and CD35 (CR1). ${ }^{37,42-45}$ Ags can remain attached to FDCs for extended periods of time; they can cycle through non-degrading compartments and resurface periodically, where they are available for acquisition by Ag-specific B cells and GC B cells. ${ }^{46,47}$

In addition to the effects of size, biophysical properties, and presence of Abs, spatiotemporal dynamics of foreign Ag acquisition by $\mathrm{B}$ cells may vary depending on the dose of $\mathrm{Ag}$, duration of its delivery to SLO, the rate of $\mathrm{Ag}$ proteolysis into smaller antigenic fragments, and clearance. It also depends on the patterns of B cell migration and localization in SLO.

\section{3 | B cell migration after Ag-dependent activation}

The coordinated migration of $\mathrm{B}$ cells following Ag stimulation depends on the expression of several different $G$ protein-coupled receptors (GPCRs) on B cells and spatial distribution of their ligands including chemokines and other factors produced by stroma and other cell types in the SLO. ${ }^{27,28}$ Follicular stromal cells express CXCL13, which promotes $B$ cell localization and migration within $B$ cell follicle via CXCR5 receptor. ${ }^{48}$ Critical to the positioning of B cells following their initial activation is the increased expression of the Epstein-Barr virus-induced protein 2 receptor (EBI2 or GPR183). ${ }^{49-51}$ EBI2 ligand, 7a,25-dihydroxycholesterol (7a,25-OHC), is located in higher concentrations at the follicular perimeter than in the center. 7a,25-OHC and EBI2 receptor promote the initial movement of activated $B$ cells toward the back of the follicle where B cells may acquire additional Ags derived from the $\mathrm{MZ}$ or $\mathrm{SC}$ sinuses. ${ }^{50-53}$ Within 6 hours following Ag stimulation, B cells upregulate the chemokine receptor CCR7, which leads to their relocalization to the border of the follicles and the CCL19 and CCL21-rich T cell zone and interfollicular regions (Figures 1C,D, and 2). ${ }^{54,55}$ Balanced responses of CXCR5, CCR7, and EBI2 receptors to their respective ligands in SLO promote migration and uniform distribution of activated $B$ cells at the T/B border, ${ }^{27,56}$ where $B$ cells may encounter cognate Th cell help and get recruited into primary T-dependent humoral immune response (Figures $1 \mathrm{C}, \mathrm{D}$, and 2 ).

\subsection{Scenarios of transient or recurrent exposure of $B$ cell to Ags in vivo}

Sequential relocalization of B cells following initial Ag-driven activation in combination with varied patterns of $\mathrm{Ag}$ distribution within SLO determines different temporal scenarios of the B cell's subsequent exposure to foreign Ags. When Ags are restricted to SCS, interfollicular,

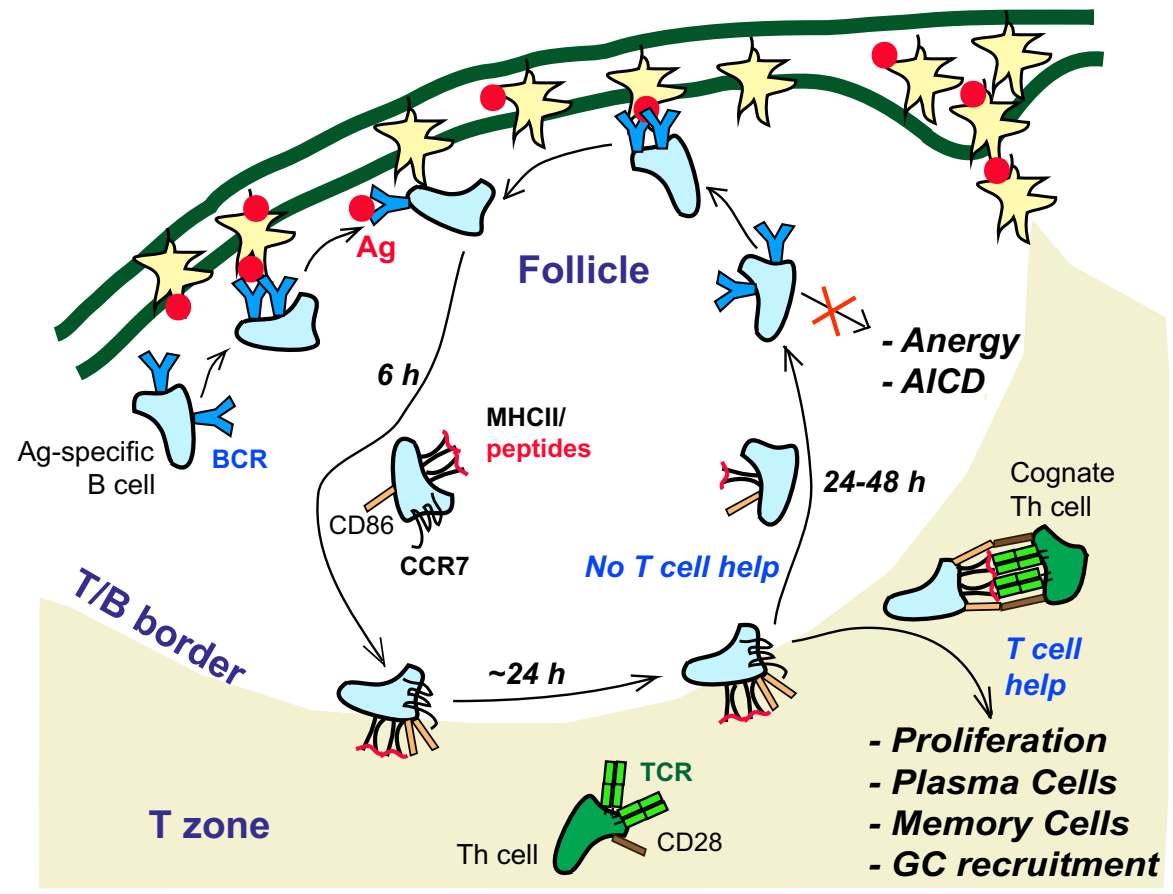

FIGURE 2 Model of B cell fate after a transient exposure to Ag. Large Ags may be initially localized to the subcapsular, medullary, cortical lymphatic sinuses and interfollicular areas. Naive B cells in the follicle randomly migrate to these regions where they can transiently acquire Ags and then leave. Ag-primed B cells relocalize to the T/B border in about $6 \mathrm{~h}$. If they acquire cognate Th cell help within $24 \mathrm{~h}$, then they proliferate and participate in the plasma cell, memory, and GC responses. If no $T$ cell help is received within this time, then $B$ cells redistribute back into the follicle and downregulate expression of Ag-derived peptide: $\mathrm{MHCll}$ complexes and activation markers. The inactivated B cells are not tolerant and do not undergo activation-induced cell death; they can reacquire Ag and T cell help and get recruited into the T-dependent B cell response. The model is suggested based on the findings in Ref. 119 
and medullary regions, $\mathrm{B}$ cell exposure to Ags (prior to their migration to T-B border) is likely to be transient (Figures $1 \mathrm{D}$ and 2). ${ }^{36,37}$ In contrast, $\mathrm{B}$ cell exposure to small Ags, which drain into B cell follicles, is likely to be more continuous (Figure $1 \mathrm{C}$ ). The continuous or recurrent exposure to $\mathrm{Ag}$ is also more likely when $\mathrm{Ag}$-immune complexes are deposited on FDCs in the middle of the follicles.

\subsection{The anatomy and timing of T cell help}

The location and timing of activated B cell's exposure to T cell help may be variable as well depending on the spatiotemporal patterns of Th cell activation in SLO, the initial frequency of the Ag-specific Th cells, and the presence of memory Th cells (in secondary immune responses).

The location of initial Ag-specific Th cells activation in SLO depends on the size and biophysical properties of the draining Ags. Small soluble Ags $(<70 \mathrm{kDa})$ can drain toward SLO and access T cell zone through the conduits that are sheathed by the fibroblastic reticular stromal cells. These Ags may be then acquired by the $\mathrm{T}$ zone-resident DCs that initiate activation of Ag-specific Th cells within $24 \mathrm{~h}$ of $\mathrm{Ag}$ administration. ${ }^{57-59}$ The Ags that are larger than $70 \mathrm{kDa}$ are usually excluded from the conduits. These Ags can gain access to the medullary region of the draining LNs and the interfollicular areas ${ }^{35,36,39,60}$ where they can be captured by the local resident DCs and presented to Ag-specific Th cells. ${ }^{61-63}$ Interestingly, some viruses (or virus-like particles, VLPs » 70 kDa) may be an exception to this rule, as they have been reported to gain some access into the $\mathrm{T}$ zone conduits and to promote local activation of Ag-specific Th cells. ${ }^{64}$ Moreover, TLR ligand-containing Q $\beta$-VLPs have been shown to engage $B$ cells to trigger efficient Th cell activation. ${ }^{65}$ In some cases, foreign Ags are presented to Th cells by the migrating tissue-derived DCs that arrive into the lymph-draining LNs with a 12-24h delay after DC maturation (reviewed in Ref. 59). This scenario may be more important for Th cell activation following infections rather than immunizations with soluble Ags. ${ }^{59,66}$

The frequency of naive Ag-specific Th cells is initially very low $\left(1: 10^{5}-10^{6}\right) .{ }^{59,67,68}$ Moreover, specific MHCll restrictions, various diseases, genetic disorders, age, and immunosuppressive therapies can further reduce the number of cognate Th cells or delay their activation. ${ }^{69,70}$ For example, HLA allotype is one of the major genetic determinants of widespread variability in immune responses to a number of vaccines, and this is attributed to variability in efficiency of binding to various antigenic peptides among classes of HLA. ${ }^{70-72}$ In all cases, when the initial frequency of Ag-specific Th cells is low, it may take a few cycles of Th cell proliferation (and a few extra days) before the Ag-primed $B$ cells become engaged in cognate encounters with activated Th cells.

In contrast to the primary immune responses, in secondary responses B-Th cell cognate interactions should occur more rapidly, both because of the increased frequencies of memory $B$ cells and memory follicular helper T cells (Tfh), as well as due to their rapid co-localization at the SCS where they can reacquire Ags and form cognate interactions. ${ }^{73-75}$
While the timing of Ag-dependent activation of B and cognate Th cells is likely to differ widely depending on multiple factors, distinct temporal scenarios of $\mathrm{Ag}$ and $\mathrm{T}$ cell help acquisition can differentially affect $B$ cell fate in vivo. This conclusion is based on the previous studies of B cell tolerance development, as well as on the more recent analysis of $B$ cell survival and recruitment into $T$-dependent responses after various modes of exposure to foreign Ags and T cell help. This we will discuss below.

\section{3 | TEMPORAL DYNAMICS OF B CELL EXPOSURE TO AG/T CELL HELP AND B CELL FATE}

As discussed above, proliferation of the Ag-specific Th cells may take a few days. The significant consequences of limiting $T$ cell help in the beginning of immune response may be a failure to recruit many of the Ag-primed $\mathrm{B}$ cells into $\mathrm{T}$-dependent response. Much of the research concerning the fate of Ag-activated B cells in the absence of $T$ cell help comes from the studies of autoimmunity. B cells specific for self-Ags are unlikely to acquire T cell help, as self-reactive T cells are thought to be removed from the proinflammatory repertoire more stringently than B cells during development. ${ }^{76}$

\section{1 | Insight from B cell exposure to self- ags and tolerance}

\subsubsection{Development of B cell anergy and AICD in B cells continuously exposed to self-Ags}

Studies of autoreactive B cells have established a consensus that to maintain tolerance, Ag-activated B cells that do not acquire $\mathrm{T}$ cell help must be removed from the responding repertoire either through receptor editing, death, or induction of an unresponsive state termed anergy. ${ }^{77,78}$ Tolerance of the primary $B$ cell repertoire to self-Ags is induced in the developing B cells, either in the bone marrow (BM) or in the spleen where $B$ cells can emigrate from the $\mathrm{BM}$ at their immature stage. Immature $\mathrm{B}$ cells that bind self-Ag with high avidity undergo receptor editing or AICD, whereas induction of anergy is observed in B cells that undergo constant but lower amplitude BCR signaling. ${ }^{79-81}$

Anergy has been first modeled in doubly transgenic (DTg) mice in which one transgene encodes a constitutively produced soluble form of the small $14 \mathrm{kDa}$ protein hen egg lysozyme (HEL), and the second encodes a HEL-specific BCR (Ig-Tg). B cells from these mice exhibit downregulation of IgM BCR. When stimulated with $\mathrm{Ag}$ and $T$ cell help in vivo, they fail to upregulate the co-stimulatory molecule CD86 and generate drastically reduced or undetectable Ab responses. ${ }^{82-84}$ In addition to reduced responsiveness to $\mathrm{Ag}$, anergic $\mathrm{B}$ cells have reduced lifespans compared to naive mature $B$ cells and, like Ag-activated non-anergic cells, are excluded from follicles and localized near the T cell zones of SLOs. ${ }^{85,86}$ In addition to HEL DTg 
mice that are characterized with very high affinity of self-Ag HEL to the Ig-Tg BCR, other transgenic models of B cell anergy that have significantly lower Ig-Tg affinity to self-Ag have been characterized and investigated. ${ }^{87-91}$ Therefore, while some differences have been reported in these mouse models, $B$ cells that have a wide range of affinities to self-Ags expressed in vivo can develop tolerance and become anergic.

Anergy development is not restricted to immature B cells and can be induced in mature $B$ cells as well. This was first shown in MD3-ML3 DTg mice that have very low levels of soluble HEL self-Ag in the uninduced state. MD3 stands for a Tg encoding HEL-specific Ig in B cells, while ML3 Tg encodes soluble HEL that is expressed from $\mathrm{Zn}$-inducible promoter. Within 2 days following $\mathrm{Zn}$-inducible overexpression of $\mathrm{HEL}$, mature Ig-Tg B cells become tolerant. ${ }^{92}$ Consistent with that, within 2 days of adoptive transfer of mature HEL-specific Ig-Tg B cells into HEL-expressing Tg ML5 mice (that constitutively express soluble HEL), their ability to mount an Ab response to immunization with HEL-HRBCs (HEL conjugated to horse red blood cells) is significantly reduced. These mature anergic Ig-Tg B cells downregulate IgM, but maintain high IgD expression, and undergo follicular exclusion and Bim-dependent disappearance within approximately 3 days. ${ }^{83,92-95}$ The observed premature death of mature B cells occurs after their continuous exposure to both soluble, as well as membrane-linked self-Ags. ${ }^{93}$

On the molecular level, anergic B cells are characterized by the elevated basal levels of intracellular $\mathrm{Ca}^{2+}$, failed mobilization of $\mathrm{Ca}^{2+}$ upon crosslinking of BCRs, increased suppression of $\mathrm{PIP}_{3}$ signaling pathway, and increased dependence on BAFF signaling to compensate for the upregulated levels of pro-apoptotic protein Bim. ${ }^{96-98}$ On the metabolic level, anergic B cells also appear to be partially quiescent. They can only modestly increase glycolysis and oxygen consumption that are significantly upregulated in activated $B$ cells and are required for Ab production. ${ }^{99}$ Finally, there is evidence for transcriptional reprogramming in anergic B cells. ${ }^{100,101}$

\subsection{2 | Anergic B cells are abundant in mice and humans}

Multiple studies suggested that anergic self-reactive $\lg D^{\text {high }} \operatorname{IgM}^{\text {low }} B$ cells are abundant among the endogenous B cells in mice and in humans. ${ }^{92,102-108}$ A large fraction of fully mature peripheral CD27 naive human $B$ cells have reduced surface expression of IgM and are enriched for autoreactive cells. These cells are hypo-responsive to $B C R$ crosslinking and exhibit poor proliferation, differentiation, and $A b$ production when stimulated with anti-IgM and anti-IgD Abs. ${ }^{106} \mathrm{~A}$ fraction of these cells are $\operatorname{lgD}^{+} \operatorname{lgM}{ }^{-}$and are called $\left[\mathrm{B}_{\mathrm{ND}}\right] \cdot{ }^{107} \mathrm{~A}$ recent study reported elevated expression of the phosphatidylinositol 3,4,5P-3phosphatase PTEN in the $\operatorname{IgD}^{+} \operatorname{IgM}^{\text {low }}$ human $B$ cells and demonstrated that PTEN was required for the maintenance of anergy in human $B$ cells and for prevention of the auto-Ab response. Interestingly, PTEN is elevated in about $40 \%$ of $C D 27^{-}$human $B$ cells and has the highest expression levels in $\operatorname{lgD}^{+} \operatorname{IgM}^{-}\left[\mathrm{B}_{\mathrm{ND}}\right]$ subset. Consistent with important role of elevated PTEN in the control of anergic autoreactive B cells in humans, in the patients with type 1 diabetics and autoimmune thyroid disease PTEN expression in B cells is reduced. ${ }^{108}$ Overall, these findings suggest that a large fraction of mature human $B$ cells are present in the periphery in an anergic state presumably due to their chronic stimulation with autoantigen and that PTEN plays an important role in the control of B cell anergy and in prevention of autoimmunity.

\subsection{3 | Rescue of B cells from tolerance by rapid T cell help}

While prolonged exposure to self-Ags promotes development of anergy and AICD in mature B cells, timely provision of T cell help can rescue these $B$ cells from development of tolerance and premature death. $T$ cell help can rescue Ig-Tg B cells (both mature and immature) even from the exposure to high-affinity membrane-bound $\mathrm{HEL}$ (mHEL) $\mathrm{Ag}$ and enables robust $G C$ and $A b$ responses by non-anergic $B$ cells even in a tolerogenic environment. ${ }^{93}$ However, $T$ cell help must be available relatively soon after the $\mathrm{Ag}$ signal (presumably within 1-2 days) to prevent induction of B cell anergy and AICD (Figure 3). ${ }^{93,109}$

\subsection{4 | Reversal of B cell anergy by removal of $\mathrm{Ag}$}

In addition to the timing of Ag-induced signals and T cell help, another factor that determines $B$ cell fate is the duration or recurrence of $\mathrm{Ag}$ exposure and continual $\mathrm{Ag}$ receptor occupancy in $\mathrm{B}$ cells. Multiple studies demonstrated that B cell anergy to self-Ag was at least partially reversed when $B$ cell exposure to cognate $A g$ was discontinued (Figure 3). Anergic DTg B cells transferred to non-Tg mice recover high surface expression of IgM and at least partially restore their ability to generate $\mathrm{Abs}$ in response to $\mathrm{Ag}$ and $\mathrm{T}$ cell help (immunization with HEL-sheep RBCs). ${ }^{110}$ The anergic B cells' AICD is discontinued after they are transferred into a naive host where they redistribute back from T-B border into $B$ cell follicles. ${ }^{83}$ Analysis of anergic $B$ cells from Ars/A1 transgenic mice (that specifically recognize foreign Ag: hapten $p$-azophenlyarsonate (Ars), as well as self$\mathrm{Ag}$ : single-stranded DNA) revealed that reduced lifespan of anergic $B$ cells depends on the chronic stimulation by self-Ag. ${ }^{90,91}$ Blocking continuous binding of Ars/A1 antigen receptor to autoantigen with monovalent ArsTyr leads to reduction of $\mathrm{Ca}^{2+}$ levels in Ars/A1 B cells to concentration of naive cells, partial restoration (50\%-75\%) of surface $\lg \mathrm{M}$, and recovery in $\mathrm{B}$ cell potential for $\mathrm{Ag}$-induced $\mathrm{Ca}^{2+}$ mobilization and CD86 upregulation ex vivo. ${ }^{111}$

\subsection{5 | Other scenarios of prevention or reversal of B cell anergy}

While removal of self- $\mathrm{Ag}$ can lead to reversal of $\mathrm{B}$ cell tolerance, in some cases B cells continuously exposed to self-Ags can be also rescued from the anergic state and AICD. 


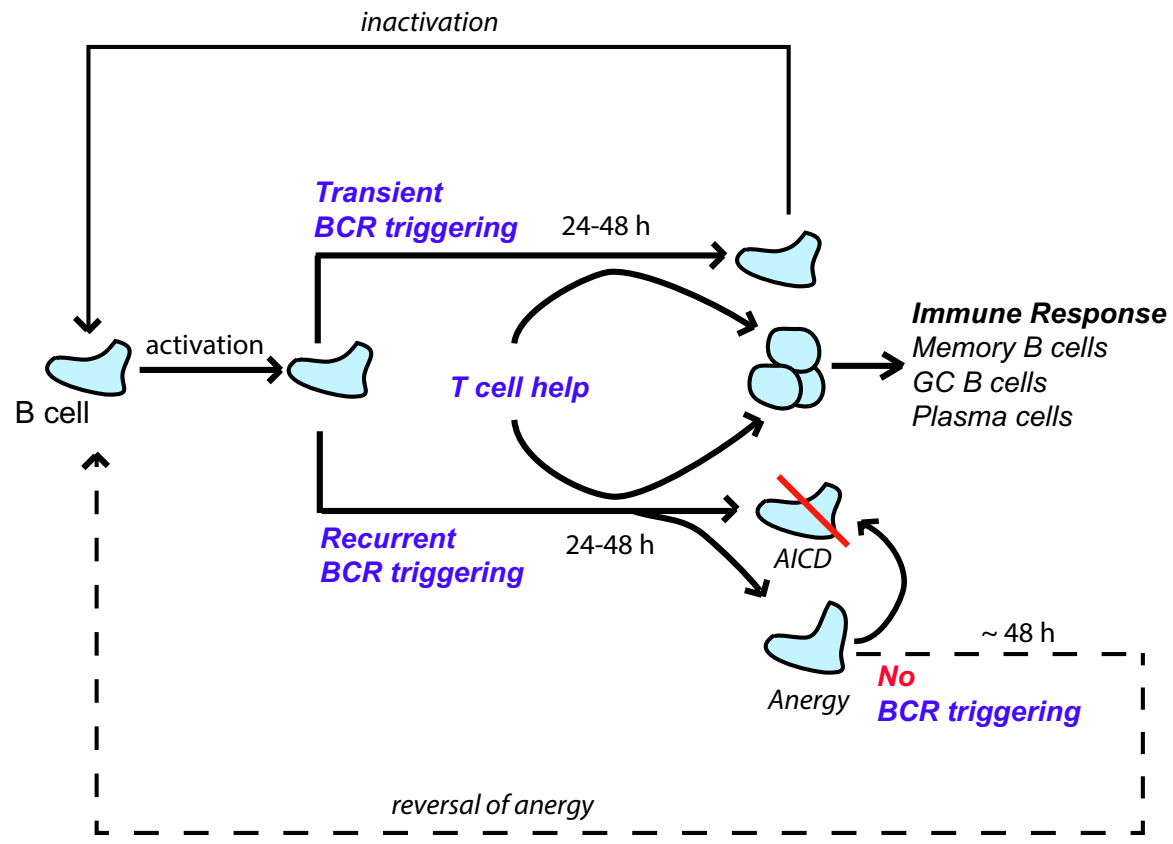

FIGURE 3 Possible scenarios of B cell fate depending on the recurrence of BCR triggering and the timing of T cell help. Transiently exposed to Ag B cells, as well as B cells that see Ag in a recurrent/continuous fashion have a 24-48 $\mathrm{h}$ window of time to acquire help from cognate Th cells. In the presence of T cell help, they proliferate and may differentiate into memory, GC, and plasma cells. In the absence of T cell help, transiently exposed to monovalent or moderately multivalent Ags B cells return to naive -like state and can reengage into immune response similarly to naive B cells. In contrast to that, B cells recurrently exposed to Ag for 24-48 $\mathrm{h}$ in the absence of T cell help may undergo AICD or become anergic. Anergic B cells are also more prone to AICD. If the exposure of anergic B cells to Ag is discontinued, then within $48 \mathrm{~h}$ their anergic state may be reversed

Overproduction of B cell pro-survival cytokine BAFF prevents development of B cell anergy and leads to autoimmunity in mice. ${ }^{112-}$ ${ }^{114}$ Consistent with a BAFF-dependent break in B cell tolerance, BAFF levels are often elevated in Lupus patients. ${ }^{115,116}$ While it has not been directly demonstrated, it is tempting to speculate that under some conditions local overproduction of BAFF by Ag-presenting or other cells in SLO may prevent B cell anergy and promote more prolonged survival of the continuously exposed to $\mathrm{Ag} B$ cells.

Exposure of anergic $B$ cells to Ags in a form of highly multivalent virus-like particles ${ }^{117}$ or in complex with complement component C $3 d^{118}$ can lead to reversal of B cell anergy and generation of PCs and autoreactive Abs. Interestingly, exposure of the anergic HELspecific Ig-Tg B cells to HEL-SRBCs Ags (that are both highly multivalent and may promote acquisition of sheep RBCs-specific T cell help) leads to efficient recruitment of the Ig- $\mathrm{Tg} B$ cells into GCs. Within GCs, they undergo rapid selection that drives their specificity away from self-Ags and toward foreign Ags. ${ }^{119-121}$ SRBC s can also promote recruitment of the endogenous $\lg D^{\text {high }} / g M^{\text {low }}$, and thus likely anergic B cells into GCs in mice. Consistent with these observations, some human memory $B$ cells and Abs elicited by immunizations have been shown to be derived from the originally autoreactive $\lg D^{\text {high }} \lg M^{\text {low }}$ B cell clones. ${ }^{119}$

While the observed possibility of a break in B cell anergy described above is potentially dangerous as a trigger for autoimmunity, it may be evolutionary important to ensure a broader repertoire of $B$ cells to respond to pathogenic Ags and for generation of $A b$ response against the pathogens that mimic self-Ags to evade host immune responses (as reviewed in Ref. 122).

\section{2 | Insight from B cell exposure to foreign Ags}

\subsection{1 | Continuous exposure to foreign Ags in the absence of T cell help promotes AICD in B cells}

In addition to AICD due to exposure to self-Ags, foreign Ags can induce cognate $B$ cell death in vivo when $T$ cell help is delayed. Similarly to the observed decay of $\mathrm{Ig}-\mathrm{Tg} B$ cells in the recipient mice that constitutively express $\mathrm{HEL}$, mature Ig-Tg B cells transferred into wildtype recipient mice start to disappear after $24 \mathrm{~h}$ of recurrent iv administration of moderately multivalent foreign Ag, DEL-OVA (duck egg lysozyme conjugated to ovalbumin) (Figure 3). ${ }^{123}$ Consistent with this, prolonged exposure of $\mathrm{Ig}-\mathrm{Tg} \mathrm{B}$ cells to cognate $\mathrm{Ag}$ in vivo has been suggested to cause mitochondrial dysfunction in Ig-Tg B cells by 24 hours after administration of a large dose of $\mathrm{Ag}(100 \mu \mathrm{g}$ HEL, Ig-Tg B cell threshold for activation is less than $20 \mathrm{ng} / \mathrm{mL}$ of $\mathrm{HEL}) .{ }^{92,124}$ In these experiments, development of mitochondrial dysfunction was inferred based on the increased MitoTracker Green staining. Development of mitochondrial dysfunction was also observed during B cell exposure to Ag ex vivo. This effect was dependent on the excessive increases in intracellular $\mathrm{Ca}^{2+}$ and correlated with B cell apoptosis. ${ }^{125}$ 


\subsection{2 | Transient exposure to Ags leads to B cell death ex vivo but not in vivo}

While persistent acquisition of $\mathrm{Ag}$ by $\mathrm{B}$ cells in the absence of $\mathrm{T}$ cell help leads to $B$ cell anergy, mitochondrial dysfunction, and death, the initial exposure of B cells to large foreign Ag in a primary immune response is likely to be transient rather than continuous (Figure 1B). The observations made by intravital two-photon imaging have raised a question whether $B$ cell fate might be different after the transient Ag acquisition. A study by Damdinsuren et al addressed this question using $B$ cells transiently primed with $\mathrm{Ag}$. The study found that a single round of BCR crosslinking stimulated transient NFKB signaling and increased $B$ cell sensitivity to CD40L, potentially priming $B$ cells to receive $T$ cell help, but was insufficient to initiate cell cycling and impaired $B$ cell survival ex vivo. ${ }^{126}$ Our recent studies confirmed that $B$ cells briefly exposed to foreign $\mathrm{Ag}$ ex vivo could be recruited into an immune response in the presence of $\mathrm{T}$ cell help in vivo (Figure 3). ${ }^{123,127,128}$ In this set of experiments, lysozyme-specific Ig-Tg B cells were incubated for 5 minutes at $37^{\circ} \mathrm{C}$ with HEL-OVA or DEL-OVA, extensively washed, and then transferred into recipient mice that were immunized with OVA in adjuvant 3 days before. In the presence of cognate $T$ cell help, these $\mathrm{Ag}$-pulsed $\mathrm{B}$ cells underwent proliferation and generated memory and GC B cells for a wide range of acquired $\mathrm{Ag}$ amounts, as well as plasmablasts (PB) at higher Ag doses. ${ }^{123}$ However, while Ag-pulsed $B$ cells underwent an expected rapid AICD in the absence of T cell help ex vivo, ${ }^{123,125,126}$ when transferred into unimmunized recipient mice, Ig-Tg B cells did not die. No Ig-Tg B cell loss (or proliferation) was observed in the SLO of unimmunized recipient mice within a week after the transfer of Ig-Tg B cells transiently pulsed ex vivo with saturating amounts of monovalent or moderately multivalent Ags. The observed survival was independent of conventional Th cells as similar persistence of Ag-pulsed $B$ cells was found in the TCR $\alpha$ KO recipient mice (Figure 3). ${ }^{123}$ To summarize the above, based on our findings and multiple previous studies, the duration of $\mathrm{B}$ cell exposure to $\mathrm{Ag}$ in the absence/delay of $\mathrm{T}$ cell help is one of the major factors that determine B cells survival vs. death in vivo. Moreover, care should be exhibited when performing analysis of $B$ cell survival ex vivo due to the enhanced apoptosis of isolated B cells in cell culture.

\subsection{3 | Transiently exposed to $\mathrm{Ag} \mathrm{B}$ cells return to "naive -like" state in vivo in the absence of rapid T cell help}

Ag-pulsed B cells first upregulate CCR7 and migrate to T/B border in the SLO of unimmunized recipient mice, but in the absence of $\mathrm{T}$ cell help they downregulate CCR7 and return to B cell follicle within 24 hours (Figure 2). They also gradually downregulate surface expression of the activation marker CD86 and MHCII/Ag peptide presentation, and within 1-2 days lose their ability to respond to $T$ cell help by proliferation. The Ag-exposed Ig-Tg B cells that return to the naive -like state are capable of responding to protein immunization similarly to naive B cells. ${ }^{123,129}$ Therefore, while transient exposure of $B$ cells to $\mathrm{Ag}$ is sufficient to prime them for $\mathrm{T}$ cell help and for their recruitment into T-dependent immune response within a time window of 1-2 days, it is not sufficient to promote B cell tolerance or AICD in vivo when T cell help is further delayed. In contrast, such B cells return to a naive -like state and are capable of efficient reengaging into immune response at later time points when additional $\mathrm{Ag}$ and $\mathrm{T}$ cell help become accessible (Figures 2 and 3). ${ }^{123,129}$

The observations that Ag-pulsed $B$ cells undergo rapid death in the absence of $T$ cell help ex vivo, but not in vivo, suggest that additional in vivo factors rescue the transiently exposed to Ag B cells from rapid AICD. This conclusion is also consistent with the observed recovery of the anergic $B$ cells' survival and responsiveness after Ag removal.

To summarize the above, B cell fate is determined in part by the duration of its exposure to $\mathrm{Ag}$, and the timing of $\mathrm{T}$ cell help. Transient exposure of $B$ cell to $\mathrm{Ag}$ (or self-Ag) enables it to be recruited into T-dependent response within 1-2 days after activation, but should not lead to removal of a given $B$ cell clone from the available repertoire if $\mathrm{T}$ cell help is missing or delayed. In contrast, continuous $\mathrm{B}$ cell exposure to cognate foreign or self-Ags can lead to AICD that obviously eliminates its ability to be recruited into response, and in the absence of properly timed provision of $\mathrm{T}$ cell help anergy can be induced. Cessation of the antigen signal terminates anergy and allows cells to return to the follicle (Figures 2 and 3 ).

\section{ANTIGEN VALENCY AND B CELL FATE}

While highly multivalent Ags are known to induce T-independent immune responses, there is still insufficient understanding of how Ags of variable valency and epitope density affect $B$ cell responses in vivo. ${ }^{130}$ In general, monovalent Ags are less likely to induce activation of $B$ cells through BCRs that have low to intermediate affinity of epitope binding, while multivalent Ags engage a broader repertoire of Ag-specific B cells due to the higher avidity of their binding to BCRs. Although there is still some debate in the field, ex vivo monovalent Ags have been shown to promote $B$ cell activation, but were less capable of efficient $\mathrm{Ag}$ presentation for Th cells. ${ }^{131-134}$ Whether poor presentation of monovalent Ags would hold in the case of B cell exposure to Ags in vivo in the context of dense cellular and molecular environment within SLO is unclear.

On the other end, hyper-crosslinking of BCRs has been shown to lead to very rapid apoptosis of mature $B$ cells ex vivo that could be partially rescued by IL4 and CD40 signaling. ${ }^{135}$ More recent analyses, that utilized glycopolymers or streptavidin-coated beads as a backbone for Ag display, confirmed correlation between Ags valency/density and the rate of cognate B cell death ex vivo. ${ }^{125,136}$ In vivo adoptive transfer of $\mathrm{Ig}-\mathrm{Tg} B$ cells into $\mathrm{mHEL}$ self-Ag-expressing mice led to somewhat faster $\mathrm{B}$ cell decline than in sHEL-expressing mice. ${ }^{93}$ Consistent with that, we found that Ig-Tg B cells transiently pulsed ex vivo with highly polyvalent Ags (polystyrene particles covered with duck egg lysozyme [DEL]) were significantly reduced in 
SLO at 7 days of their transfer into recipient mice: an outcome that was not observed with more moderately valent Ags, even at saturating concentrations for Ig-Tg B cells. ${ }^{123}$ To summarize the above, the ex vivo and preliminary in vivo data suggest that in the absence of $T$ cell help highly multivalent foreign Ags may induce more potent or rapid AICD in B cells. However, more in-depth analysis of this phenomenon is required.

\section{5 | CELLULAR ENVIRONMENT OF AG ACQUISITION AND B CELL FATE}

\subsection{Ag encounter by B cells occurs in the context of contact with other cells}

Other than B cells that enter SLO after acquisition of Ag in the blood or lymph, B cells that encounter cognate Ags in SLO parenchyma should see it mostly in the context of other cells. Foreign Ags can be immobilized on the surface of Ag-presenting cells bound via $\mathrm{Fc}$ and complement receptors or more specific receptors for glycosylated Ags, such as DC-SIGN (reviewed in Ref. 23,24). Other Ags that are not physically tethered to cell surface are distributed in between various cells in the interfollicular and medullary regions (eg, large particular Ags), or are found in the follicles in association with follicular stromal conduits and possibly outside the conduits in between follicular B cells (small soluble Ags). All of these sites are fairly densely filled with various kinds of stromal cells, lymphocytes, DCs, macrophages, and other cell types that are present at different frequencies in different locations. Therefore, even none membranetethered Ags should be mostly recognized by B cells in the context of contact with other cells.

While some of the factors produced locally by the $M \Phi, D C s$, and stromal cells may promote T-independent or amplify T-dependent $B$ cell responses (as discussed in the earlier section of this review), others may potentially affect $B$ cell fate during the process of $A g$ acquisition and while $B$ cells are waiting for $T$ cell help.

\section{2 | Sialic ligands on the surface of Ag-presenting cells may influence $B$ cell fate}

T and B lymphocytes, as well as multiple other cell types, are covered with glycans that could modulate $B$ cell responsiveness and fate after their exposure to membrane-associated self-Ags. ${ }^{137}$ An insight into this regulation arises from the studies of membrane-bound selfAgs that induce more potent tolerance in B cells than soluble Ags. ${ }^{79-}$ ${ }^{81,93}$ In part, this may be due to more multivalent high avidity mode of binding and thus more potent engagement of BCRs and signaling. However, B cell tolerance to membrane-bound self-Ags is further ensured by specific interactions between type-I transmembrane lectin proteins (Siglecs) and species-specific sialic acid motifs that are present on glycans on the surface of most cells (Reviewed in Ref. 137-140).
Two types of Siglecs lectins, CD22 and Siglec-G, are preferentially expressed on $B$ cells ${ }^{140}$ and can bind to their ligands both in cis (on the surface of the same cell) or in trans (on the neighboring cells). ${ }^{141-143}$ Co-presentation of Ag with Siglecs' sialic acid ligands on Ag-presenting cells was shown to promote suppression of BCR signaling and induce an apoptotic signal in cognate $B$ cells ex vivo. This result suggested a possible role of Siglec/Siglec ligand interactions in the mechanisms of self vs non-self-discrimination. ${ }^{142}$ The mechanism involves phosphorylation of Siglec's cytoplasmic ITIM motifs through recruitment of phosphotyrosine and phosphoinositide phosphatases SHP-1 and SHIP, leading to dephosphorylation of BCR signaling machinery and downstream targets. ${ }^{142,144-146}$ In addition to the ex vivo observations, recognition of Ags in conjunction with CD22 and Siglec G siglec ligands has been shown to induce B cell tolerance in vivo ${ }^{147}$ and to prevent development of autoAbs. ${ }^{141,148-151}$

An elegant study illuminated the role of interactions between CD22 and Siglec G receptors and sialic acids for induction of tolerance in mature B cells. ${ }^{152}$ The study used an adoptive transfer model to address the proliferation and survival of mature $\mathrm{HEL}$-specific Ig-Tg $B$ cells upon their in vivo exposure to $B$ cells expressing their cognate $\mathrm{Ag} \mathrm{HEL}$ in membrane-attached form (mHEL). Co-expression of CD22 and Siglec G on Ig-Tg B cells was required for efficient inhibition of their proliferation and rapid death in the presence of $\mathrm{mHEL}$ expressing B cells. Conversely, deficiency in the preferred ligands of CD22 ( $\alpha$ 2-6 linked sialosides) on mHEL-presenting ST6Gal1 ${ }^{-1-}$ B cells (that lack the enzyme, which catalyzes transfer of sialic acid from CMPsialic acid to galactose-containing substrates) ${ }^{153}$ was sufficient to partially restore Ig-Tg B cell proliferation and survival. ${ }^{152}$ The study also demonstrated that CD22 and Siglec-G have distinct partially redundant specificities for sialic ligands on the cell surface and can be recruited to the immunological synapse with Ag-presenting cells independently of each other. It also suggested that B cell deletion requires participation of Lyn kinase and pro-apoptotic factor BIM. ${ }^{152}$

Overall, these and other studies indicate that in the context of membrane-bound Ags, CD22 and Siglec G-mediated recognition of species-specific natural sialic ligands by $B$ cells (in trans) and their recruitment into immunological synapse should potentiate $B$ cell tolerance and death in vivo. It is not known if natural sialic ligands are expressed by the specialized intact Ag-presenting cells (such as SCS macrophages and FDCs) and contribute to defining B cell fate to foreign Ags in vivo.

\subsection{Acquisition of $\mathrm{Ag}$ in the context of FDCs and $\mathrm{B}$ cell fate}

One of the key questions is whether recognition of Ags by naive $B$ cells obeys the rules for the induction of tolerance and AICD in $B$ cells when $\mathrm{Ag}$ is presented on FDCs. It has been shown that immune complexes that are deposited on FDCs and are thus displayed in a highly repetitive fashion can trigger T-independent responses and even promote formation of GCs in nude mice. ${ }^{154,155}$ The data suggest that Ags displayed as immune complexes on FDCs can promote 
Ag-specific B cells to proliferate and initiate early PB and GC responses even when $T$ cell help is not available, ${ }^{155}$ possibly due to the contribution of co-stimulatory factors (BAFF, IL-6 and C4bBP) produced by FDCs.

However, another study suggested that tolerance develops in Ig-Tg B cells that encounter self-Ags on FDCs. The study utilized $\mathrm{CD} 21^{\text {cre }} \mathrm{mDEL}{ }^{\text {loxP }}$ mice (that express membrane-bound DEL on FDCs and $B$ cells) that were irradiated and reconstituted with MD4 BM cells to investigate lysozyme-specific Ig-Tg B cell tolerance toward self-Ag DEL expressed by FDCs. ${ }^{156}$ In these mice, transitional and follicular Ig-Tg B cells were significantly reduced and B cells escaping negative selection had upregulated BIM and were more prone to apoptosis. Interestingly, in contrast to the "classical" anergic B cells, BCR signaling in the lysozyme-specific Ig-Tg B cells appeared to be intact.

The differences in the results described above could be possibly explained by the distinct mouse models that have been utilized, presentation of immune complexes with foreign Ags vs directly membrane-attached self-Ags on FDCs, or differential effects that Ags presented on FDCs exert on the developing vs. mature B cells. It remains to be sorted out under which conditions the Ags presented on FDCs promote T-independent amplification of B cell responses or may lead to induction of B cell tolerance, especially when $T$ cell help to $B$ cells is delayed.

\section{6 | REMAINING QUESTIONS AND CONCLUDING NOTES}

The original "Signal 1 and 2" model for B cell activation and recruitment into T-dependent response vs development of tolerance has been very attractive due to its simplicity and binary predictions. However, based on the previous studies and the emerging data, significantly more sophisticated scenario of B cell fate decisionmaking is likely to take place in vivo. While the timing of $\mathrm{T}$ cell help availability is one of the major factors that should define B cell fate, for a given $B$ cell clone it may also depend on the type of $A g$ that the $B$ cell encounters, where this encounter(s) occurs, for how long it proceeds, and which additional signals $\mathrm{B}$ cells receive from $\mathrm{Ag}$ presenting and neighboring cells. Performed herein analysis of diverse spatiotemporal scenarios of $\mathrm{Ag}$ and $\mathrm{T}$ cell help availability for $B$ cells in SLO together with the ex vivo/in vivo experimental studies of $B$ cell activation and tolerance suggest that $B$ cell recruitment into $\mathrm{T}$-dependent response in vivo may be influenced by (a) duration of $B$ cell exposure to foreign $\mathrm{Ag}$ and timing of $\mathrm{T}$ cell help, (b) the valency of $\mathrm{Ag}$, and (c) the cellular context of $\mathrm{Ag}$ acquisition. It also reveals outstanding gaps in our understanding of these processes that should be further addressed. Below we suggest a few questions that emerge from the findings discussed in this review.

Q1: For a given B cell, duration of its exposure to $\mathrm{Ag}$ prior to acquisition of $\mathrm{T}$ cell help determines the likelihood of its tolerance and rapid death. A lot has been learned about the molecular mechanisms of B cell activation and anergy. ${ }^{157,158}$ However, the remaining fundamental questions is how BCR signaling is integrated over time on the molecular level to determine B cell fate: anergy, mitochondrial dysfunction, and ultimately AICD vs. B cell deactivation and return to naive -like state in vivo? Does the "molecular integrator" solely depend on the duration of BCR engagement or is BCR signaling strength also incorporated into the decision circuit? Q2: Briefly exposed to Ag B cells undergo rapid apoptosis ex vivo but not in vivo, which should be considered in the studies of $B$ cell activation, survival, and metabolism. Which factors rescue the survival of $\mathrm{B}$ cells briefly exposed to $\mathrm{Ag}$ in vivo? BAFF (Blys) is one of the factors that is likely to contribute to Ag-primed $B$ cell survival. ${ }^{159,160}$ However, whether additional signaling molecules and pathways, such as Notch, integrin, or migration-promoting chemokine signaling, ${ }^{161}$ may contribute to the rescue of $\mathrm{Ag}$ primed $B$ cells from untimely AICD must be further elucidated.

Q3: While our previous evidence suggests no substantial difference in the responsiveness of naive vs. naive -like (briefly exposed to $\mathrm{Ag}$ and then inactivated) B cells to protein immunization, future studies should address whether some transcriptional or metabolic differences persist over time and may affect long-term B cell survival in SLO or influence their fate after they differentiate into GC, PC, or memory B cells.

Q4: Short-term exposure to $\mathrm{Ag}$ is, presumably, not sufficient to induce mitochondrial dysfunction in B cells in vivo. However, what is the interrelationship between B cell anergy and mitochondrial dysfunction? Do all anergic B cells develop mitochondrial dysfunction? Are tolerant B cells that develop profound mitochondrial dysfunction destined to die? Can mitochondrial dysfunction be reversed in anergic B cells after disruption of continuous engagement of BCRs?

Q5: Previous studies suggested that there are profound transcriptional differences in the anergic compared to the recently activated B cells. ${ }^{100,101}$ However, it remains to be assessed whether these changes are permanent or whether they disappear within some time after B cells exposure to Ags in vivo has been discontinued.

Q6: Additional in vivo studies are necessary to test various models of highly multivalent Ags. We need to better understand how the physico-chemical characteristics of Ags (including variable Ag concentrations, size, valencies, and epitope densities, together with other biophysical properties of the Ags) affect the activation versus tolerance outcomes for B cells in vivo and their recruitment into the $\mathrm{PC}$ and GC response. ${ }^{130}$

Recent studies have opened a new dimension of the pro-survival or pro-death signals that may be encountered by $B$ cells during the process of $\mathrm{Ag}$ acquisition in SLO in proximity to various distinct Ag-presenting or neighboring cells. At the moment, this leaves us with multiple opened questions on how the local environment of $\mathrm{Ag}$ acquisition by naive $\mathrm{B}$ cells affects their fate and ability to get recruited into T-dependent response vs. undergo rapid death. Among these questions are the following: 
Q7: Are sialic acid ligands for CD22 and Siglec-G expressed at sufficient levels on Ag-presenting cells, such as macrophages, DCs, or FDCs for triggering B cell tolerance?

Q8: Are transient encounters with cells expressing membrane selfAgs and sialic ligands for CD22/Siglec-G sufficient to trigger B cell's $A I C D$ in vivo or are prolonged/recurrent encounters required?

Q9: Can sialic ligands contribute to B cell apoptosis when Ags are presented as immune complexes rather than transmembrane or directly membrane-attached proteins?

Q10: Small soluble Ags that drain into the SLO can be acquired in close proximity to other B cells that express sialic ligands of CD22/ Siglec G. Because of this proximity, can sialic ligands/Siglec interactions contribute to the induction of B cell AICD by soluble Ags in vivo? Q11: Can other signals (eg, BAFF, Notch ligands, integrins, chemokines, or other factors) expressed by the Ag-presenting cells rescue $B$ cells from apoptosis (or promote it) when $T$ cell help is delayed in vivo.

\section{7 | CONCLUDING NOTES}

Cumulatively, multiple factors discussed in this review affect the diversity of $\mathrm{B}$ cell clones recruited into $\mathrm{T}$-dependent responses to foreign Ags, as well as the ultimate fate of those cells. It is important to note that in the case of multicomponent vaccines or pathogen infections, $\mathrm{B}$ cells reactive with various Ags or antigenic fragments are likely to have differential spatiotemporal patterns of exposure to those epitopes in vivo and therefore may have distinct fates.

From the other hand, biophysical properties of self-Ags and the duration of their access to SLO may also determine whether self-reactive B cells become anergic and are removed from B cell repertoire or persist, enabling their potential recruitment into responses to foreign- or self-Ags. By dissecting the still unresolved questions about $B$ cell fate in the context of various scenarios of $\mathrm{Ag}$ and $\mathrm{T}$ cell help acquisition in vivo, we should arrive at a more comprehensive "Signal 1, $2+$ " model that would enable better manipulation of T-dependent $\mathrm{B}$ cell responses for vaccination or therapeutic purposes.

\section{ACKNOWLEDGEMENTS}

We thank W. Dunnick and J. Cambier for useful discussions and for reading the manuscript. Supported by the Herman and Dorothy Miller Award for Innovative Immunology Research to JST and ZLB, and National Institute of Health (R01 Al106806) to IG The authors declare no competing financial interests.

\section{ORCID}

Irina L. Grigorova (iD https://orcid.org/0000-0002-4963-7403

\section{REFERENCES}

1. Bretscher P, Cohn M. A theory of self-nonself discrimination. Science. 1970;169(3950):1042-1049.
2. Rock KL, Benacerraf B, Abbas AK. Antigen presentation by hapten-specific B lymphocytes. I. Role of surface immunoglobulin receptors. J Exp Med. 1984;160(4):1102-1113.

3. Mond JJ, Vos Q, Lees A, Snapper CM. T cell independent antigens. Curr Opin Immunol. 1995;7(3):349-354.

4. Mond JJ, Lees A, Snapper CM. T cell-independent antigens type 2. Annu Rev Immunol. 1995;13:655-692.

5. Garcia de Vinuesa C, O'Leary P, Sze DM, Toellner KM, MacLennan IC. T-independent type 2 antigens induce $B$ cell proliferation in multiple splenic sites, but exponential growth is confined to extrafollicular foci. Eur J Immunol. 1999;29(4):1314-1323.

6. Vinuesa CG, Chang P-P. Innate B cell helpers reveal novel types of antibody responses. Nat Immunol. 2013;14(2):119-126.

7. Liao W, Hua Z, Liu C, Lin L, Chen R, Hou B. Characterization of T-dependent and T-independent $\mathrm{B}$ cell responses to a virus-like particle. J Immunol. 2017;198(10):3846-3856.

8. Obukhanych TV, Nussenzweig MC. T-independent type II immune responses generate memory B cells. J Exp Med. 2006;203(2):305-310.

9. Haas KM, Poe JC, Steeber DA, Tedder TF. B-1a and B-1b cells exhibit distinct developmental requirements and have unique functional roles in innate and adaptive immunity to $S$. pneumoniae. Immunity. 2005;23(1):7-18.

10. Bortnick A, Chernova I, Quinn WJ, Mugnier M, Cancro MP, Allman D. Long-lived bone marrow plasma cells are induced early in response to $\mathrm{T}$ cell-independent or $\mathrm{T}$ cell-dependent antigens. J Immunol. 2012;188(11):5389-5396.

11. Kurosaki T, Kometani K, Ise W. Memory B cells. Nat Rev Immunol. 2015;15(3):149-159.

12. Defrance T, Taillardet M, Genestier L. T cell-independent B cell memory. Curr Opin Immunol. 2011;23(3):330-336.

13. Victora GD, Nussenzweig MC. Germinal centers. Annu Rev Immunol. 2012;30:429-457.

14. MacLennan IC. Germinal centers. Annu Rev Immunol. 1994;12:117-139.

15. Nutt SL, Hodgkin PD, Tarlinton DM, Corcoran LM. The generation of antibody-secreting plasma cells. Nat Rev Immunol. 2015;15(3):160-171.

16. Dosenovic P, Kara EE, Pettersson AK, et al. Anti-HIV-1 $B$ cell responses are dependent on B cell precursor frequency and antigen-binding affinity. Proc Natl Acad Sci USA. 2018;115(18):4743-4748.

17. Abbott RK, Lee JH, Menis S, et al. Frequency and affinity determine $\mathrm{B}$ cell competitive fitness in germinal centers, tested with germline-targeting HIV vaccine immunogens. Immunity. 2018;48(1):133-146.e6.

18. Havenar-Daughton C, Abbott RK, Schief WR, Crotty S. When designing vaccines, consider the starting material: the human $B$ cell repertoire. Curr Opin Immunol. 2018;53:209-216.

19. Batista FD, Neuberger MS. Affinity dependence of the B cell response to antigen: a threshold, a ceiling, and the importance of off-rate. Immunity. 1998;8(6):751-759.

20. Shih TA, Meffre E, Roederer M, Nussenzweig MC. Role of BCR affinity in T cell dependent antibody responses in vivo. Nat Immunol. 2002;3(6):570-575

21. Taylor JJ, Pape KA, Steach HR, Jenkins MK. Humoral immunity. Apoptosis and antigen affinity limit effector cell differentiation of a single naive B cell. Science. 2015;347(6223):784-787.

22. Schwickert TA, Victora GD, Fooksman DR, et al. A dynamic T cell-limited checkpoint regulates affinity-dependent B cell entry into the germinal center. J Exp Med. 2011;208(6):1243-1252.

23. Batista FD, Harwood NE. The who, how and where of antigen presentation to B cells. Nat Rev Immunol. 2009;9(1):15-27.

24. Phan TG, Gray EE, Cyster JG. The microanatomy of B cell activation. Curr Opin Immunol. 2009;21(3):258-265. 
25. Harwood NE, Batista FD. Antigen presentation to B cells. F1000 Biol Rep. 2010;2:87.

26. Gonzalez SF, Degn SE, Pitcher LA, Woodruff M, Heesters BA, Carroll MC. Trafficking of B cell antigen in lymph nodes. Annu Rev Immunol. 2011;29:215-233.

27. Pereira JP, Kelly LM, Cyster JG. Finding the right niche: B-cell migration in the early phases of T-dependent antibody responses. Int Immunol. 2010;22(6):413-419.

28. Cyster JG. B cell follicles and antigen encounters of the third kind. Nat Immunol. 2010;11(11):989-996.

29. Reboldi A, Cyster JG. Peyer's patches: organizing B-cell responses at the intestinal frontier. Immunol Rev. 2016;271(1):230-245.

30. Gretz JE, Norbury CC, Anderson AO, Proudfoot AE, Shaw S. Lymph-borne chemokines and other low molecular weight molecules reach high endothelial venules via specialized conduits while a functional barrier limits access to the lymphocyte microenvironments in lymph node cortex. J Exp Med. 2000;192(10):1425-1440.

31. Nolte MA, Belien JA, Schadee-Eestermans I, et al. A conduit system distributes chemokines and small blood-borne molecules through the splenic white pulp. J Exp Med. 2003;198(3):505-512.

32. Pape KA, Catron DM, Itano AA, Jenkins MK. The humoral immune response is initiated in lymph nodes by $B$ cells that acquire soluble antigen directly in the follicles. Immunity. 2007;26:491-502.

33. Catron DM, Pape KA, Fife BT, van Rooijen N, Jenkins MK. A protease-dependent mechanism for initiating T-dependent B cell responses to large particulate antigens. J Immunol. 2010;184(7):3609-3617.

34. Roozendaal R, Mempel TR, Pitcher LA, et al. Conduits mediate transport of low-molecular-weight antigen to lymph node follicles. Immunity. 2009;30(2):264-276.

35. Grigorova IL, Panteleev M, Cyster JG. Lymph node cortical sinus organization and relationship to lymphocyte egress dynamics and antigen exposure. Proc Natl Acad Sci USA. 2010;107(47):20447-20452.

36. Carrasco YR, Batista FD. B cells acquire particulate antigen in a macrophage-rich area at the boundary between the follicle and the subcapsular sinus of the lymph node. Immunity. 2007;27(1):160-171.

37. Phan TG, Grigorova I, Okada T, Cyster JG. Subcapsular encounter and complement-dependent transport of immune complexes by lymph node B cells. Nat Immunol. 2007;8(9):992-1000.

38. Junt T, Moseman EA, lannacone M, et al. Subcapsular sinus macrophages in lymph nodes clear lymph-borne viruses and present them to antiviral B cells. Nature. 2007;450(7166):110-114.

39. Gonzalez SF, Lukacs-Kornek V, Kuligowski MP, et al. Capture of influenza by medullary dendritic cells via SIGN-R1 is essential for humoral immunity in draining lymph nodes. Nat Immunol. 2010;11(5):427-434

40. Qi H, Egen JG, Huang AY, Germain RN. Extrafollicular activation of lymph node B cells by antigen-bearing dendritic cells. Science. 2006;312(5780):1672-1676.

41. Bergtold A, Desai DD, Gavhane A, Clynes R. Cell surface recycling of internalized antigen permits dendritic cell priming of B cells. Immunity. 2005;23(5):503-514.

42. Brown JC, De Jesus DG, Holborow EJ, Harris G. Lymphocytemediated transport of aggregated human gamma-globulin into germinal centre areas of normal mouse spleen. Nature. 1970;228(5269):367-369.

43. Heinen E, Braun M, Coulie PG, et al. Transfer of immune complexes from lymphocytes to follicular dendritic cells. Eur J Immunol. 1986;16(2):167-172.

44. Ferguson AR, Youd ME, Corley RB. Marginal zone B cells transport and deposit IgM-containing immune complexes onto follicular dendritic cells. Int Immunol. 2004;16(10):1411-1422.
45. Cinamon G, Zachariah MA, Lam OM, Foss FW Jr, Cyster JG. Follicular shuttling of marginal zone $B$ cells facilitates antigen transport. Nat Immunol. 2008;9(1):54-62.

46. Heesters BA, Chatterjee P, Kim Y-A, et al. Endocytosis and recycling of immune complexes by follicular dendritic cells enhances B cell antigen binding and activation. Immunity. 2013;38(6): 1164-1175.

47. Suzuki K, Grigorova IL, Phan TG, Kelly LM, Cyster JG. Visualizing B cell capture of cognate antigen from follicular dendritic cells. J Exp Med. 2009;206(7):1485-1493.

48. Ansel KM, Ngo VN, Hyman PL, et al. A chemokine-driven positive feedback loop organizes lymphoid follicles. Nature. 2000;406(6793):309-314.

49. Liu C, Yang XV, Wu J, et al. Oxysterols direct B-cell migration through EBI2. Nature. 2011;475(7357):519-523.

50. Pereira JP, Kelly LM, Xu Y, Cyster JG. EBI2 mediates B cell segregation between the outer and centre follicle. Nature. 2009;460(7259):1122-1126.

51. Yi T, Wang X, Kelly LM, et al. Oxysterol gradient generation by lymphoid stromal cells guides activated $B$ cell movement during humoral responses. Immunity. 2012;37(3):535-548.

52. Kelly LM, Pereira JP, Yi T, Xu Y, Cyster JG. EBI2 guides serial movements of activated $B$ cells and ligand activity is detectable in lymphoid and nonlymphoid tissues. J Immunol. 2011;187(6):3026-3032

53. Hannedouche $\mathrm{S}$, Zhang J, Yi T, et al. Oxysterols direct immune cell migration via EBI2. Nature. 2011;475(7357):524-527.

54. Reif K, Ekland EH, Ohl L, et al. Balanced responsiveness to chemoattractants from adjacent zones determines B-cell position. Nature. 2002;416(6876):94-99.

55. Okada T, Miller MJ, Parker I, et al. Antigen-engaged B cells undergo chemotaxis toward the $\mathrm{T}$ zone and form motile conjugates with helper T cells. PLoS Biol. 2005;3(6):e150.

56. Gatto D, Wood K, Brink R. EBI2 operates independently of but in cooperation with CXCR5 and CCR7 to direct B cell migration and organization in follicles and the germinal center. J Immunol. 2011;187(9):4621-4628.

57. Garside P, Ingulli E, Merica RR, Johnson JG, Noelle RJ, Jenkins MK. Visualization of specific $B$ and $T$ lymphocyte interactions in the lymph node. Science. 1998;281(5373):96-99.

58. Sixt M, Kanazawa N, Selg M, et al. The conduit system transports soluble antigens from the afferent lymph to resident dendritic cells in the T cell area of the lymph node. Immunity. 2005;22(1):19-29.

59. Itano AA, Jenkins MK. Antigen presentation to naive CD4 T cells in the lymph node. Nat Immunol. 2003;4(8):733-739.

60. Lin Y, Louie D, Ganguly A, Wu D, Huang P, Liao S. Elastin shapes small molecule distribution in lymph node conduits. J Immunol. 2018;200(9):3142-3150.

61. Gerner MY, Casey KA, Kastenmuller W, Germain RN. Dendritic cell and antigen dispersal landscapes regulate $T$ cell immunity. $J$ Exp Med. 2017;214(10):3105-3122.

62. Gerner MY, Torabi-Parizi P, Germain RN. Strategically localized dendritic cells promote rapid $\mathrm{T}$ cell responses to lymph-borne particulate antigens. Immunity. 2015;42(1):172-185.

63. Woodruff MC, Heesters BA, Herndon $\mathrm{CN}$, et al. Trans-nodal migration of resident dendritic cells into medullary interfollicular regions initiates immunity to influenza vaccine. J Exp Med. 2014;211(8):1611-1621.

64. Reynoso GV, Weisberg AS, Shannon JP, et al. Lymph node conduits transport virions for rapid T cell activation. Nat Immunol. 2019;20(5):602-612

65. Hong S, Zhang Z, Liu H, et al. Cells are the dominant antigen-presenting cells that activate naive CD4(+) T cells upon Immunization with a virus-derived nanoparticle antigen. Immunity. 2018;49(4):695-708.e4 
66. Lee HK, Zamora M, Linehan MM, et al. Differential roles of migratory and resident DCs in T cell priming after mucosal or skin HSV-1 infection. J Exp Med. 2009;206(2):359-370.

67. Moon JJ, Chu HH, Pepper M, et al. Naive CD4(+) T cell frequency varies for different epitopes and predicts repertoire diversity and response magnitude. Immunity. 2007;27(2):203-213.

68. Gudmundsdottir H, Wells AD, Turka LA. Dynamics and requirements of $\mathrm{T}$ cell clonal expansion in vivo at the single-cell level: effector function is linked to proliferative capacity. J Immunol. 1999;162(9):5212-5223.

69. Frasca D, Riley RL, Blomberg BB. Humoral immune response and B-cell functions including immunoglobulin class switch are downregulated in aged mice and humans. Semin Immunol. 2005;17(5):378-384.

70. de Bruyn G. Cofactors that may influence vaccine responses. Curr Opin HIV AIDS. 2010;5(5):404-408.

71. Tan PL, Jacobson RM, Poland GA, Jacobsen SJ, Pankratz VS. Twin studies of immunogenicity-determining the genetic contribution to vaccine failure. Vaccine. 2001;19(17-19):2434-2439.

72. Hohler T, Reuss E, Evers N, et al. Differential genetic determination of immune responsiveness to hepatitis $B$ surface antigen and to hepatitis A virus: a vaccination study in twins. Lancet. 2002;360(9338):991-995.

73. Ma CS, Phan TG. Here, there and everywhere: $T$ follicular helper cells on the move. Immunology. 2017;152(3):382-387.

74. Suan D, Nguyen A, Moran I, et al. T follicular helper cells have distinct modes of migration and molecular signatures in naive and memory immune responses. Immunity. 2015;42(4):704-718.

75. Moran I, Nguyen A, Khoo WH, et al. Memory B cells are reactivated in subcapsular proliferative foci of lymph nodes. Nat Commun. 2018;9(1):3372.

76. Nossal GJV. Negative selection of lymphocytes. Cell. 1994;76(2):229-239.

77. Nossal GJ, Pike BL. Clonal anergy: persistence in tolerant mice of antigen-binding B lymphocytes incapable of responding to antigen or mitogen. Proc Natl Acad Sci USA. 1980;77(3):1602-1606.

78. Matzinger P. Tolerance, danger, and the extended family. Annu Rev Immunol. 1994;12:991-1045.

79. Hartley SB, Crosbie J, Brink R, Kantor AB, Basten A, Goodnow $C C$. Elimination from peripheral lymphoid tissues of self-reactive B lymphocytes recognizing membrane-bound antigens. Nature. 1991;353(6346):765-769.

80. Tiegs SL, Russell DM, Nemazee D. Receptor editing in self-reactive bone marrow B cells. J Exp Med. 1993;177(4):1009-1020.

81. Gay D, Saunders T, Camper S, Weigert M. Receptor editing: an approach by autoreactive B cells to escape tolerance. J Exp Med. 1993;177(4):999-1008.

82. Goodnow CC, Crosbie J, Adelstein S, et al. Altered immunoglobulin expression and functional silencing of self-reactive $B$ lymphocytes in transgenic mice. Nature. 1988;334(6184):676-682.

83. Cyster JG, Goodnow CC. Antigen-induced exclusion from follicles and anergy are separate and complementary processes that influence peripheral B cell fate. Immunity. 1995;3(6):691-701.

84. Bell SE, Goodnow CC. A selective defect in IgM antigen receptor synthesis and transport causes loss of cell surface IgM expression on tolerant B lymphocytes. EMBO J. 1994;13(4):816-826.

85. Cyster JG, Hartley SB, Goodnow CC. Competition for follicular niches excludes self-reactive cells from the recirculating B-cell repertoire. Nature. 1994;371(6496):389-395.

86. Fulcher DA, Basten A. Reduced life span of anergic self-reactive B cells in a double-transgenic model. J Exp Med. 1994;179(1): 125-134.

87. Erikson J, Radic MZ, Camper SA, Hardy RR, Carmack C, Weigert $M$. Expression of anti-DNA immunoglobulin transgenes in non-autoimmune mice. Nature. 1991:349(6307):331-334.
88. Nguyen KA, Mandik L, Bui A, et al. Characterization of anti-single-stranded DNA B cells in a non-autoimmune background. J Immunol. 1997;159(6):2633-2644.

89. Shlomchik MJ, Aucoin AH, Pisetsky DS, Weigert MG. Structure and function of anti-DNA autoantibodies derived from a single autoimmune mouse. Proc Natl Acad Sci USA. 1987;84(24):9150-9154.

90. Wysocki LJ, Sato VL. The strain A anti-p-azophenylarsonate major cross-reactive idiotypic family includes members with no reactivity toward p-azophenylarsonate. Eur J Immunol. 1981;11(10):832-839.

91. Benschop RJ, Aviszus K, Zhang X, Manser T, Cambier JC, Wysocki LJ. Activation and anergy in bone marrow $B$ cells of a novel immunoglobulin transgenic mouse that is both hapten specific and autoreactive. Immunity. 2001;14(1):33-43.

92. Goodnow CC, Crosbie J, Jorgensen H, Brink RA, Basten A. Induction of self-tolerance in mature peripheral B lymphocytes. Nature. 1989;342(6248):385-391.

93. Fulcher DA, Lyons $A B$, Korn SL, et al. The fate of self-reactive $B$ cells depends primarily on the degree of antigen receptor engagement and availability of $\mathrm{T}$ cell help. J Exp Med. 1996;183(5):2313-2328.

94. Enders A, Bouillet $\mathrm{P}$, Puthalakath $\mathrm{H}, \mathrm{Xu}$ Y, Tarlinton DM, Strasser A. Loss of the pro-apoptotic $\mathrm{BH} 3$-only $\mathrm{Bcl}-2$ family member Bim inhibits BCR stimulation-induced apoptosis and deletion of autoreactive B cells. J Exp Med. 2003;198(7):1119-1126.

95. Lesley R, Xu Y, Kalled SL, et al. Reduced competitiveness of autoantigen-engaged $\mathrm{B}$ cells due to increased dependence on BAFF. Immunity. 2004;20(4):441-453.

96. Yarkoni Y, Getahun A, Cambier JC. Molecular underpinning of B-cell anergy. Immunol Rev. 2010;237(1):249-263.

97. Browne $C D$, Del Nagro $C J$, Cato $M H$, Dengler HS, Rickert RC. Suppression of phosphatidylinositol 3,4,5-trisphosphate production is a key determinant of B cell anergy. Immunity. 2009;31(5):749-760.

98. Getahun A, Beavers NA, Larson SR, Shlomchik MJ, Cambier JC. Continuous inhibitory signaling by both SHP-1 and SHIP-1 pathways is required to maintain unresponsiveness of anergic B cells. J Exp Med. 2016;213(5):751-769.

99. Caro-Maldonado A, Wang R, Nichols AG, et al. Metabolic reprogramming is required for antibody production that is suppressed in anergic but exaggerated in chronically BAFF-exposed B cells. J Immunol. 2014;192(8):3626-3636.

100. Glynne R, Akkaraju S, Healy JI, Rayner J, Goodnow CC, Mack DH. How self-tolerance and the immunosuppressive drug FK506 prevent B-cell mitogenesis. Nature. 2000;403(6770):672-676.

101. Sabouri Z, Perotti S, Spierings E, et al. IgD attenuates the IgMinduced anergy response in transitional and mature B cells. Nat Commun. 2016;7:13381.

102. Merrell KT, Benschop RJ, Gauld SB, et al. Identification of anergic B cells within a wild-type repertoire. Immunity. 2006;25(6): 953-962.

103. Wardemann H, Yurasov S, Schaefer A, Young JW, Meffre E, Nussenzweig MC. Predominant autoantibody production by early human B cell precursors. Science. 2003;301(5638):1374-1377.

104. Zikherman J, Parameswaran R, Weiss A. Endogenous antigen tunes the responsiveness of naive B cells but not $T$ cells. Nature. 2012;489(7414):160-164.

105. Noorchashm H, Bui A, Li HL, et al. Characterization of anergic anti-DNA B cells: B cell anergy is a T cell-independent and potentially reversible process. Int Immunol. 1999;11(5):765-776.

106. Quach TD, Manjarrez-Orduno N, Adlowitz DG, et al. Anergic responses characterize a large fraction of human autoreactive naive B cells expressing low levels of surface IgM. J Immunol. 2011:186(8):4640-4648. 
107. Duty JA, Szodoray P, Zheng NY, et al. Functional anergy in a subpopulation of naive $B$ cells from healthy humans that express autoreactive immunoglobulin receptors. J Exp Med. 2009;206(1):139-151.

108. Smith MJ, Ford BR, Rihanek M, et al. Elevated PTEN expression maintains anergy in human $B$ cells and reveals unexpectedly high repertoire autoreactivity. JCI Insight. 2019;4(3):e123384.

109. Cook MC, Basten A. Fazekas de St. Groth B. Rescue of self-reactive $\mathrm{B}$ cells by provision of $\mathrm{T}$ cell help in vivo. Eur J Immunol. 1998;28(8):2549-2558.

110. Goodnow CC, Brink R, Adams E. Breakdown of self-tolerance in anergic B lymphocytes. Nature. 1991;352(6335):532-536.

111. Gauld SB, Benschop RJ, Merrell KT, Cambier JC. Maintenance of $B$ cell anergy requires constant antigen receptor occupancy and signaling. Nat Immunol. 2005;6(11):1160-1167.

112. Mackay F, Schneider P, Rennert P, Browning J. BAFF AND APRIL: a tutorial on B cell survival. Annu Rev Immunol. 2003;21:231-264.

113. Mackay F, Woodcock SA, Lawton P, et al. Mice transgenic for BAFF develop lymphocytic disorders along with autoimmune manifestations. J Exp Med. 1999;190(11):1697-1710.

114. Thien M, Phan TG, Gardam S, et al. Excess BAFF rescues self-reactive $B$ cells from peripheral deletion and allows them to enter forbidden follicular and marginal zone niches. Immunity. 2004;20(6):785-798.

115. Becker-Merok A, Nikolaisen C, Nossent HC. B-lymphocyte activating factor in systemic lupus erythematosus and rheumatoid arthritis in relation to autoantibody levels, disease measures and time. Lupus. 2006;15(9):570-576.

116. Petri M, Stohl W, Chatham W, et al. Association of plasma B lymphocyte stimulator levels and disease activity in systemic lupus erythematosus. Arthritis Rheum. 2008;58(8):2453-2459.

117. Chackerian B, Durfee MR, Schiller JT. Virus-like display of a neoself antigen reverses $B$ cell anergy in a $B$ cell receptor transgenic mouse model. J Immunol. 2008;180(9):5816-5825.

118. Lyubchenko T, Dal Porto JM, Holers VM, Cambier JC. Cutting edge: complement (C3d)-linked antigens break B cell anergy. J Immunol. 2007;179(5):2695-2699.

119. Sabouri Z, Schofield P, Horikawa K, et al. Redemption of autoantibodies on anergic B cells by variable-region glycosylation and mutation away from self-reactivity. Proc Natl Acad Sci USA. 2014;111(25):E2567-E2575.

120. Chan TD, Wood K, Hermes JR, et al. Elimination of germinal-center-derived self-reactive $B$ cells is governed by the location and concentration of self-antigen. Immunity. 2012;37(5):893-904.

121. Burnett DL, Langley DB, Schofield P, et al. Germinal center antibody mutation trajectories are determined by rapid self/foreign discrimination. Science. 2018;360(6385):223-226.

122. Rosenspire AJ, Chen K. Anergic B cells: precarious on-call warriors at the nexus of autoimmunity and false-flagged pathogens. Front Immunol. 2015;6:580.

123. Turner JS, Marthi M, Benet ZL, Grigorova I. Transiently antigen-primed $B$ cells return to naive-like state in absence of T-cell help. Nat Commun. 2017;8:15072.

124. Cook MC, Basten A, de St F, Groth B. Outer periarteriolar lymphoid sheath arrest and subsequent differentiation of both naive and tolerant immunoglobulin transgenic $B$ cells is determined by $B$ cell receptor occupancy. J Exp Med. 1997;186(5):631-643.

125. Akkaya M, Traba J, Roesler AS, et al. Second signals rescue B cells from activation-induced mitochondrial dysfunction and death. Nat Immunol. 2018;19(8):871-884.

126. Damdinsuren $B$, Zhang $Y$, Khalil A, et al. Single round of antigen receptor signaling programs naive $B$ cells to receive $T$ cell help. Immunity. 2010;32(3):355-366.

127. Turner JS, Benet ZL, Grigorova IL. Antigen acquisition enables newly arriving $B$ cells to enter ongoing immunization-induced germinal centers. J Immunol. 2017;199(4):1301-1307.
128. Turner JS, Benet ZL, Grigorova I. Transiently antigen primed B cells can generate multiple subsets of memory cells. PLoS ONE. 2017;12(8):e0183877.

129. Turner JS, Ke F, Grigorova I. B cells transiently exposed to antigen that return to quiescence respond to protein immunization similarly to naive B cells. bioRxiv. 2018. https://doi.org/10.1101/303420

130. Cheng W. The density code for the development of a vaccine? J Pharm Sci. 2016;105(11):3223-3232.

131. Ubelhart R, Hug E, Bach MP, et al. Responsiveness of B cells is regulated by the hinge region of IgD. Nat Immunol. 2015;16(5):534-543.

132. Bennett NR, Zwick DB, Courtney AH, Kiessling LL. Multivalent antigens for promoting $B$ and T cell activation. ACS Chem Biol. 2015;10(8):1817-1824.

133. Kim YM, Pan JY, Korbel GA, Peperzak V, Boes M, Ploegh HL. Monovalent ligation of the $B$ cell receptor induces receptor activation but fails to promote antigen presentation. Proc Natl Acad Sci USA. 2006;103(9):3327-3332.

134. Minguet S, Dopfer EP, Schamel WW. Low-valency, but not monovalent, antigens trigger the B-cell antigen receptor (BCR). Int Immunol. 2010;22(3):205-212.

135. Parry SL, Hasbold J, Holman M, Klaus GG. Hypercross-linking surface IgM or IgD receptors on mature $B$ cells induces apoptosis that is reversed by costimulation with IL-4 and anti-CD40. J Immunol. 1994;152(6):2821-2829.

136. Qin Q, Yin Z, Wu X, Haas KM, Huang X. Valency and density matter: deciphering impacts of immunogen structures on immune responses against a tumor associated carbohydrate antigen using synthetic glycopolymers. Biomaterials. 2016;101:189-198.

137. Macauley MS, Crocker PR, Paulson JC. Siglec-mediated regulation of immune cell function in disease. Nat Rev Immunol. 2014;14(10):653-666

138. Nitschke L. CD22 and Siglec-G regulate inhibition of B-cell signaling by sialic acid ligand binding and control B-cell tolerance. Glycobiology. 2014;24(9):807-817.

139. Chen GY, Brown NK, Zheng P, Liu Y. Siglec-G/10 in self-nonself discrimination of innate and adaptive immunity. Glycobiology. 2014;24(9):800-806.

140. Muller J, Nitschke L. The role of CD22 and Siglec-G in B-cell tolerance and autoimmune disease. Nat Rev Rheumatol. 2014;10(7):422-428.

141. Crocker PR, Paulson JC, Varki A. Siglecs and their roles in the immune system. Nat Rev Immunol. 2007;7(4):255-266.

142. Lanoue A, Batista FD, Stewart M, Neuberger MS. Interaction of CD22 with alpha2,6-linked sialoglycoconjugates: innate recognition of self to dampen B cell autoreactivity? Eur J Immunol. 2002;32(2): 348-355.

143. Collins BE, Blixt O, DeSieno AR, Bovin N, Marth JD, Paulson JC. Masking of CD22 by cis ligands does not prevent redistribution of CD22 to sites of cell contact. Proc Natl Acad Sci USA 2004;101(16):6104-6109.

144. Tedder TF, Tuscano J, Sato S, Kehrl JH. CD22, a B lymphocyte-specific adhesion molecule that regulates antigen receptor signaling. Annu Rev Immunol. 1997;15:481-504.

145. Doody GM, Justement LB, Delibrias CC, et al. A role in B cell activation for CD22 and the protein tyrosine phosphatase SHP Science. 1995;269(5221):242-244.

146. Poe JC, Fujimoto M, Jansen PJ, Miller AS, Tedder TF. CD22 forms a quaternary complex with SHIP, Grb2, and Shc. A pathway for regulation of $B$ lymphocyte antigen receptor-induced calcium flux. J Biol Chem. 2000;275(23):17420-17427.

147. Duong BH, Tian $\mathrm{H}$, Ota T, et al. Decoration of T-independent antigen with ligands for CD22 and Siglec-G can suppress immunity and induce B cell tolerance in vivo. J Exp Med. 2010;207(1):173-187.

148. Poe JC, Tedder TF. CD22 and Siglec-G in B cell function and tolerance. Trends Immunol. 2012;33(8):413-420. 
149. Pillai S, Netravali IA, Cariappa A, Mattoo H. Siglecs and immune regulation. Annu Rev Immunol. 2012;30:357-392.

150. Paulson JC, Macauley MS, Kawasaki N. Siglecs as sensors of self in innate and adaptive immune responses. Ann N Y Acad Sci. 2012;1253:37-48.

151. Jellusova J, Nitschke L. Regulation of B cell functions by the sialic acid-binding receptors siglec-G and CD22. Front Immunol. 2011;2:96.

152. Macauley MS, Paulson JC. Siglecs induce tolerance to cell surface antigens by BIM-dependent deletion of the antigen-reactive $B$ cells. J Immunol. 2014;193(9):4312-4321.

153. Powell LD, Sgroi D, Sjoberg ER, Stamenkovic I, Varki A. Natural ligands of the $\mathrm{B}$ cell adhesion molecule CD22 beta carry $\mathrm{N}$-linked oligosaccharides with alpha-2,6-linked sialic acids that are required for recognition. J Biol Chem. 1993;268(10):7019-7027.

154. El Shikh ME, El Sayed RM, Szakal AK, Tew JG. T-independent antibody responses to T-dependent antigens: a novel follicular dendritic cell-dependent activity. J Immunol. 2009;182(6):3482-3491.

155. El Shikh ME, El Sayed RM, Sukumar S, Szakal AK, Tew JG. Activation of B cells by antigens on follicular dendritic cells. Trends Immunol. 2010;31(6):205-211.

156. Yau IW, Cato MH, Jellusova J, Hurtado de Mendoza T, Brink R, Rickert RC. Censoring of self-reactive $B$ cells by follicular dendritic cell-displayed self-antigen. J Immunol. 2013;191(3):1082-1090.
157. Packard TA, Cambier JC. B lymphocyte antigen receptor signaling: initiation, amplification, and regulation. F1000Prime Rep. 2013;5:40.

158. Franks SE, Cambier JC. Putting on the Brakes: regulatory kinases and phosphatases maintaining B cell anergy. Front Immunol. 2018;9:665.

159. Gardam S, Brink R. Non-canonical NF-kappaB signaling Initiated by BAFF influences $B$ cell biology at multiple junctures. Front Immunol. 2014;4:509.

160. Goenka R, Scholz JL, Sindhava VJ, Cancro MP. New roles for the BLyS/BAFF family in antigen-experienced B cell niches. Cytokine Growth Factor Rev. 2014;25(2):107-113.

161. Lim VY, Zehentmeier S, Fistonich C, Pereira JP. A chemoattractant-guided walk through lymphopoiesis: from hematopoietic stem cells to mature B lymphocytes. Adv Immunol. 2017;134:47-88.

How to cite this article: Turner JS, Benet ZL, Grigorova IL. Signals 1, 2 and B cell fate or: Where, when and for how long?. Immunol Rev. 2020;296:9-23. https://doi.org/10.1111/ imr.12865 